\title{
Corrigendum to "Seroprevalence of Dengue IgG Antibodies among Healthy Adult Population in Lahore, Pakistan"
}

\author{
Shahid Mahmood, ${ }^{1}$ Hibbah Nabeel, ${ }^{2}$ Saadia Hafeez, ${ }^{2}$ Urooj Zahra, ${ }^{2}$ and Hammad Nazeer ${ }^{3}$ \\ ${ }^{1}$ Department of Community Medicine, Gujranwala Medical College, Gujranwala, Pakistan \\ ${ }^{2}$ Fatima Jinnah Medical College, Lahore, Pakistan \\ ${ }^{3}$ Department of Infectious Diseases, Shaukat Khanum Memorial Hospital, Lahore, Pakistan
}

Correspondence should be addressed to Shahid Mahmood; shahidsethi@hotmail.com

Received 6 November 2017; Accepted 8 November 2017; Published 22 November 2017

Copyright (C) 2017 Shahid Mahmood et al. This is an open access article distributed under the Creative Commons Attribution License, which permits unrestricted use, distribution, and reproduction in any medium, provided the original work is properly cited.

In the article titled "Seroprevalence of Dengue IgG Antibodies among Healthy Adult Population in Lahore, Pakistan" [1], the name of the second author was given incorrectly as Hiba Nabeel. The author's name should have been written as Hibbah Nabeel. The revised authors' list is shown above.

\section{References}

[1] S. Mahmood, H. Nabeel, S. Hafeez, U. Zahra, and H. Nazeer, "Seroprevalence of Dengue IgG Antibodies among Healthy Adult Population in Lahore, Pakistan," ISRN Tropical Medicine, vol. 2013, pp. 1-6, 2013. 


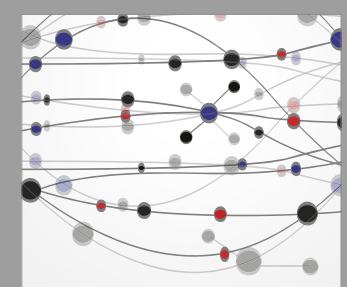

The Scientific World Journal
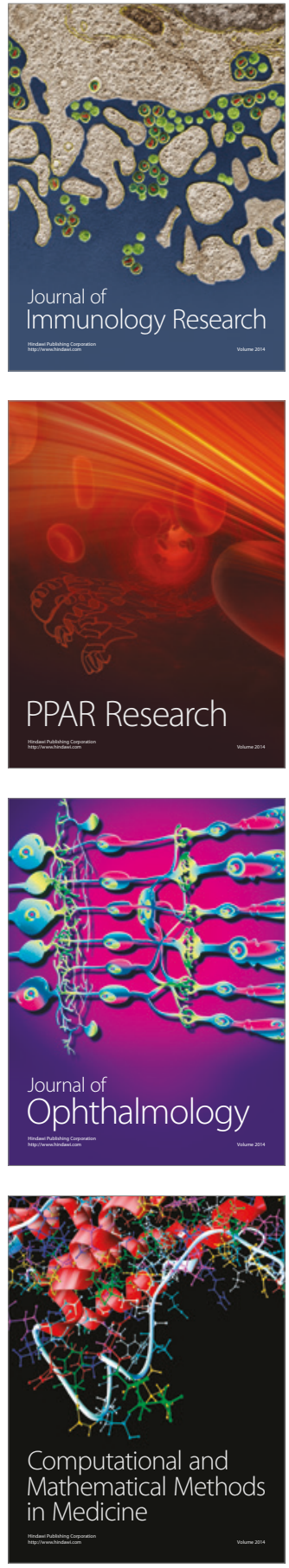

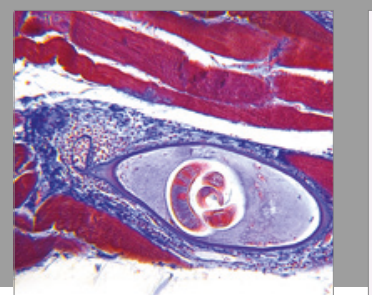

Gastroenterology Research and Practice
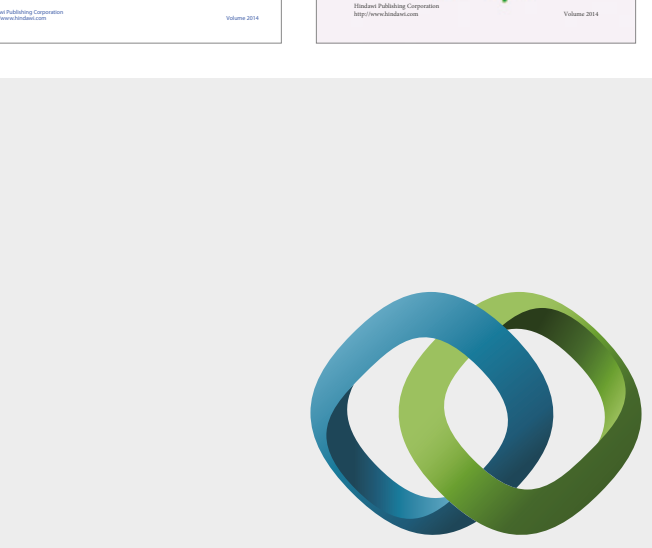

\section{Hindawi}

Submit your manuscripts at

https://www.hindawi.com
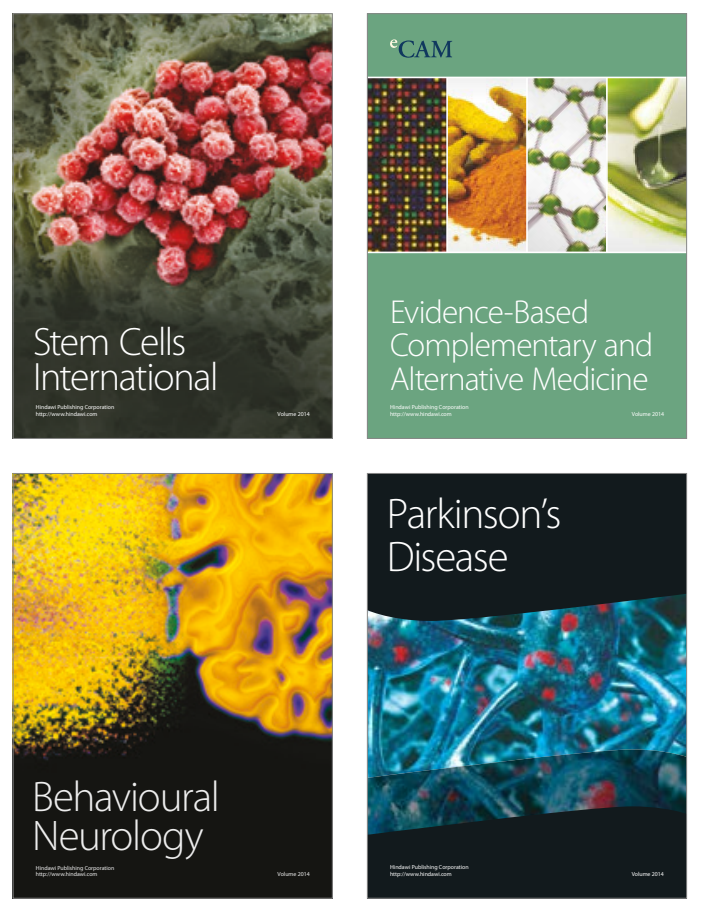
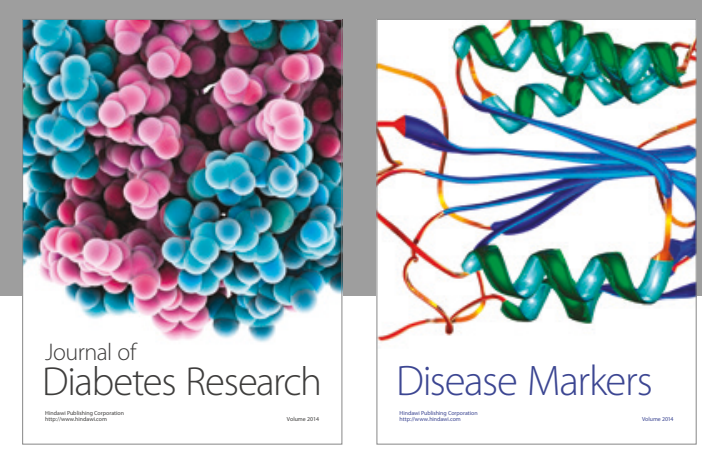

Disease Markers
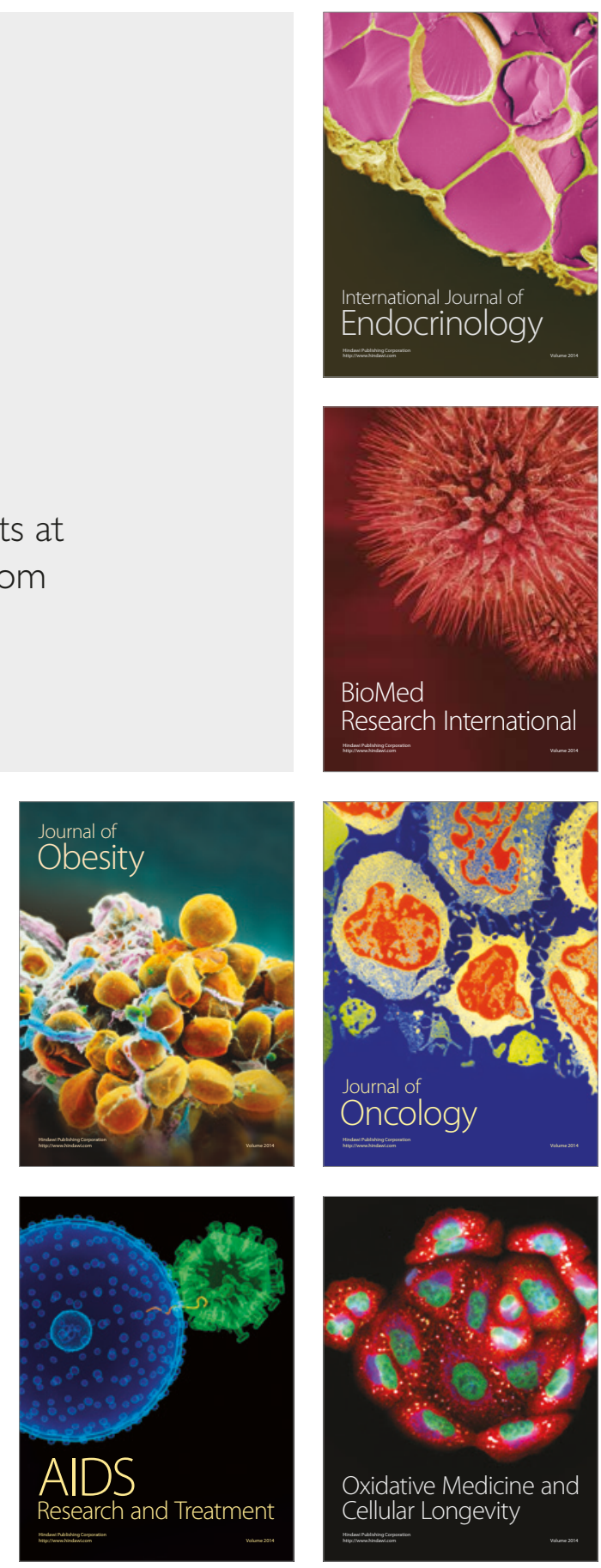